\title{
EDITORIAL
}

\section{Headache in Childhood and Adolescence}

\author{
A Challenge in Acute Medicine and Public Health
}

Peter Weber

Editorial to accompany the review by Andreas Straube et al. „Headache in school children: prevalence and risk factors" in this issue of Deutsches Ärzteblatt International

University Children's Hospital Basel (UKBB):

Prof. Dr. med. Dipl.Psych. Weber eadaches are the most common type pain symptom in childhood and adolescence; they not only create difficulties for the patient and his/her family, but may also cause the treating physician to shake his head. The concerns of the parents become those of the physician and as a result headaches are the most reason for referring school children for tertiary pediatric neurology consultation (1). The first question concerns the possible causes: how certain can the physician be when employing just history and clinical examination that he/ she is not dealing with symptomatic (secondary) headaches, especially as a sign of an underlying a brain tumor? The next question is the diagnosis of what type of headache: how reliable and valid are the international criteria for the classification of headaches in children and adolescents? Even after the physician has decided his/her patient has chronic primary headaches, a third question remains to be answered: what is the appropriate management in this special age group. The article in this issue of Deutsches Ärtzeblatt International by Straube et al. (2) reviews this complex subject while providing some answers for these practical daily questions.

\section{Diagnostic approach and diagnosis}

Headaches are the most common primary symptom for brain tumors in children, present in $40-60 \%$ of patients $(3,4)$, but are only very rarely an isolated symptom. Instead they are usually associated with cranial nerve deficits or other focal neurologic findings.

A variety of „red flags“ help to distinguish clinically between primary and secondary headaches in children; they include acute headache, rapid progression of intensity and/or frequency, change in character of headache, morning headaches with vomiting on an empty stomach, being awakened by headaches, additional focal neurologic symptoms, personality changes, and age $>3$ years $(5)$.

More difficult is fitting the headache into one of the categories of primary headache according to the criteria of the International Headache Society. Straube et al. (2) show clearly that the accuracy with which childhood migraines and tension headaches can be separated is age-dependent, which has led to the introduction into the daily routine of other, more practical diagnostic algorithms (6).
Chronic diseases in children and adolescents undergo a developmental processs. As the child or adolescent develops, his/her self-perception also undergoes changes. Both positive somatic sensations as well as pain are interpreted differently as both the body and psyche mature. Pain perception changes along with self-perception and can be more adequately verbally described. Along with the neurobiologic aspects, such as maturation of pain sensors, and the psychological aspects of changing pain perceptions, one must also consider the changing familial, social and environmental factors which all lead to an increase in prevalence of chronic headaches from childhood to adolescence and to an altered clinical pattern for migraines (7). There are both age-specific symptoms and age-dependent risk factors which must be explored with a language appropriate for the patient's age. In younger patients, nonverbal methods are often useful, such as having the child draw their headache. This double development-both the normal maturation process and changes in clinical symptomatology-must be considered in the diagnostic approach.

The diagnosis of chronic headaches requires not only careful attention to the nature of the pain but also an assessment of psychosocial consequences, such as staying home from school because of pain, which can be a grave problem in children with migraines (8). The headache history seems banal but in daily practice it is the key to diagnosis and the basis for therapeutic decisions.

\section{Multi-dimensional therapeutic approach}

Chronic headaches in children and adolescents are a perfect example of a disease for which no single approach, such as pharmacologic therapy, is sufficient. By evaluating the risk factors, Straube et al. (2) underscore the importance of a multi-dimensional approach, which has become established in pediatric pain centers and should always be considered in the routine care of these children and their families. The article confirms many commonly discussed possible trigger or aggravating factors, such as social problems in the peer group, and scrutinizes other assumptions such as the alleged role of inadequate fluid intake. Incorporating all this information into the routine evaluation of childhood headache patients requires adjustments in practice 
routine with resultant economic compensation, something which is not easily achieved today.

\section{Therapy and Prevention}

The treatment of chronic headaches in school children starts with a counseling session - not with a prescription pad, even though this may seem simpler to both affected families and the physician.

The identification of risk factors that are more likely to trigger or worsen, rather than directly cause, headaches in school children makes possible a variety of secondary preventive measures. Improving the child's self-image and resilience, helping them develop coping strategies, and enhancing the social competence of fellow students and teachers all are desirable. One option for a system-directed invention is special learning projects, such as discussions on conflict management in the daily routine at school. In addition, teachers can be involved, making clear to them the medical situation of the student and the possible relationship between the school environment and his/her illness. All of these should help to reduce stress factors. One should also be sensitive to stress within the family and the problem of over-organization of a child's daily schedule. Inquiring about sensory overload and recovery times in the child's daily routine is an essential part of the physician's approach to diagnosis and therapy.

The emphasis on the child's personal resources and on enhancing coping abilities has a proven role in the treatment of chronic pain in school children; this applies to headaches as well as other pain (9). The question we have to ask ourselves is - do we have enough experienced personnel and dedicated centers to provide such services in a competent fashion for as long as the child needs them. From the vantage point of the physician and psychotherapist, efforts must be made to develop, use and evaluate new forms of intervention (10).

A multi-dimensional approach is essential for tertiary prevention. The ,natural“ course of chronic headaches in school children indicates not only an increased risk for headaches as an adult (11) but also for other organic and psychiatric problems (12).

\section{Conclusion}

Pain-free development is one of most self-evident goals that we must strive to obtain for the children and adolescents of our society. Even in patients with a biological predisposition for chronic headaches we can help with secondary and tertiary preventive measures. The article by Straube et al. helps us develop routine thera- peutic and social medicine approaches directed both to the individual patient and to our societal systems.

\section{Conflict of interest statement \\ The author declares that no conflict of interest exists.}

Translated from the original German by Walter Burgdorf, MD.

\section{REFERENCES}

1. Dooley JM, Gordon KE, Wood EP, CamfieldCS, Camfield PR: The utility of the physical examination and investigations in the pediatric neurology Consultation. Pediatric Neurology 2005; 28: 96-9.

2. Straube A, Heinen F, Ebinger F, von Kries R: Headache in school children: prevalence and risk factors. Dtsch Arztebl Int 2013; 110(48): 811-18.

3. Wilne SH, Ferris RC, Nathwani A, Kennedy CR: The presenting features of brain tumours: a review of 200 cases. Arch Disease Child 2006; 91: 502-6.

4. Reulecke BC, Erker CG, Fiedler BJ, Niederstadt TU, Kurlemann G: Brain tumors in children: initial symptoms and their influence on the time span between symptom onset and diagnosis. J Child Neurol 2008; 23: 178-83

5. Parisi P, Papetti L, Spalice A, Nicita F, Ursitti F, Villa MP: Tension-type headache in pediatric age. Acta Paediatrica 2011; 100: 491-5.

6. Jacobs H, Gladstein J: Pediatric headache: a clinical review. Headache 2012; 52: 333-9.

7. Guidett V, Galli F, Termine C: Headache in children. Handb Clin Neurol 2010; 97: 739-54.

8. Hershey AD, Powers SW, Vockell ALB, LeCates S, Kabbouche MA, Maynard MK: Development of a questionnaire to assess disability of migraines in children. Neurology 2001; 57: 2034-9.

9. Eccleston C, Palermo TM, Williams ACDC, et al.: Psychological therapies for the management of chronic and recurrent pain in children and adolescents. Cochrane Database Sys Rev 2012; 12 : CD003968.

10. Trautmann E, Kröner-Herwig B: A randomized controlled trial of Internet-based self-help training for recurrent headache in childhood and adolescence. Behaviour Research Therapy 2010; 48: 28-37.

11. Brna P, Dooley J, Gordon K, Dewan T: The prognosis of childhood headache. Arch Pediatr Adolesc Med 2005; 159: 1157-60.

12. Fearon P, Hotopf M: Relation between headache in childhood and physical and psychiatric symptoms in adulthood: national birth cohort study. BMJ 2001; 322: 1-6.

\section{Corresponding author:}

Prof. Dr. med. Dipl.Psych. Peter Weber

University Children's Hospital Basel

Spital Str. 33

4056 Basel, Switzerland

peter.weber@ukbb.ch

\section{Cite this as:}

Weber P: Headache in childhood and adolescence-a challenge in acute medicine and public health. Dtsch Arztebl Int 2013; 110(48): 809-10. DOl: $10.3238 /$ arztebl.2013.0809 